Article

\title{
Smart and Sustainable eMaintenance: Capabilities for Digitalization of Maintenance
}

\author{
Niklas Johansson, Eva Roth and Wiebke Reim * $\mathbb{D}$ \\ Entrepreneurship and Innovation, Luleå University of Technology, 97187 Luleå, Sweden \\ * Correspondence: wiebke.reim@ltu.se
}

Received: 31 May 2019; Accepted: 24 June 2019; Published: 28 June 2019

check for updates

\begin{abstract}
In the era of Industry 4.0, researchers have begun to more thoroughly examine digital maintenance, i.e., eMaintenance, as digitization is increasingly affecting today's society. This area is particularly interesting in the case of long-life components such as those used in the mining and transport industries. With eMaintenance, the correct type of maintenance can be utilized and the frequency for device maintenance can be reduced through real-time diagnosis. This leads to reduced costs for companies that implement eMaintenance as well as environmental benefits through improved resource utilization. Advantages of eMaintenance have been described in the literature; however, the capabilities necessary to implement eMaintenance lack proper research. The purpose of this study is to develop a framework that presents the required capabilities and their connection when an organization wants to implement eMaintenance, as well as to identify the outcomes of the transition to eMaintenance. The study is based on an exploratory case study that includes 26 interviews with a digital railway maintenance development company and its main customer, the traffic agency. The study findings are presented in a framework, including five main capabilities for implementing eMaintenance and its relationship within the noted industries. The required capabilities are, namely, digital technology development, organizational development, change of work routines, compliance with regulations, and assuring information security. The framework also analyzes the outcomes of implementing digital maintenance, which demonstrate a variety of economic, environmental, and social benefits.
\end{abstract}

Keywords: eMaintenance; digitalization; Industry 4.0; digital maintenance; railway maintenance; smart maintenance; sustainability

\section{Introduction}

In today's society, we are constantly connected with the help of smartphones and computers [1]; further, according to Iansiti and Lakhani [2], the number of connected products has increased explosively in recent years. Products that were once completely mechanical or electronic now include increasingly more complex functions [3]. In recent years, many companies have chosen to follow digital trends and use more smart and connected devices to find new ways to create and deliver value, which is referred to as digitization, Internet of things (IoT), or Industry 4.0 [4-7]. These new units open up additional ways to create and capture value through a change in digitization-based business models $[3,8]$. This new technology drives companies to undergo comprehensive digital transformation [1,9]. Digital transformation can be defined as processes in which digital technology is used to create new approaches to do business by replacing traditional approaches [9].

Maintenance has for a long time been one of the focal areas for research on digitalization. Within all types of maintenance work, it must be possible to quickly discover the reasons for errors, remedies, and improvements for future products [10]. Therefore, digital maintenance or eMaintenance has received increasing attention over the recent years [11]. Digital maintenance or eMaintenance can 
be described as the area of maintenance where technology is used to provide decision support for operations and maintenance, through the application of advanced information technology [12]. eMaintenance requires not only technical solutions to bring about a functioning system, but the entire organization, external actors, and their working methods are changed when going from traditional maintenance to eMaintenance [11].

One goal of digitizing maintenance is to find ways to reduce the remedial maintenance and work more with condition-based maintenance, as it saves both time and money for the companies [13]. Porter and Heppelmann [3] reveal how real-time transmission of data describing a device's condition allows companies to optimize maintenance when faults on the device are about to occur, thereby reducing the time when the device is not functional. However, difficulties with such systems include the ability to filter all available data in order to discern what is relevant. Another difficulty is that the operations manual when collecting data can be interpreted differently depending on who reads it. By analyzing large amounts of data, instead, patterns can be identified automatically, which leads to higher reliability when it comes to finding errors that must be addressed [13].

Digital maintenance, or eMaintenance, is a relatively young area for which little research has been conducted. There is a lot of research within, for example, Industry 4.0, i.e., digitization of production lines, but not much in regard to digital maintenance. The existing research touches upon the results that eMaintenance makes possible, but the path to it, i.e., the actual implementation, is frequently highlighted as an area that requires more research [14]. Implementing eMaintenance can be seen as a digital transformation of an organization, and eMaintenance would benefit from in-depth research focusing on what is required to change the approaches from several perspectives. There is currently no clear understanding of how organizations can organize the implementation of eMaintenance.

Therefore, the purpose of this study is to develop a framework that presents the required capabilities and their connection when an organization is required to implement eMaintenance as well as to identify the outcomes of the transition to eMaintenance. Through a case study, where the focus is on digitization of railway maintenance, the capabilities and outcomes are identified, and their relationships are analyzed in order for a company to follow the digital trend and implement digitization of maintenance.

\section{Theoretical Background}

\subsection{Digital Transformation}

In order for a company to step into the digital world, in addition to digitizing its products and services, it also needs to digitize its strategies, working methods, and business models through digital transformation $[4,7]$. The new technologies, along with digital tools and working methods, are the basis for this development [1,9]. Literature on Industry 4.0 and IoT has made great advances in the past to facilitate the technological development of digital applications. Furthermore, Legner et al. [4] revealed that access to all digital tools contributes to more companies cooperating with research institutes to increase their innovation and competitiveness. In order for a company to utilize digital technology and carry out a digital transformation, it is required that the entire organization undergo a major change regarding organizational structure, strategies, IT architecture, working methods, and business models $[1,8,15]$. A critical part is to ensure that the company's digital and business strategies are adapted to each other and to the IT systems and processes used [16]. According to Matt et al. [6], there are four important aspects to consider when designing a digital transformation strategy: technology; changes in value-creating activities; structural changes; and financial aspects. A company needs to make complex decisions on what and how to handle the available technologies, e.g., if it chooses to develop it itself or use existing technical solutions [6,7].

When a company carries out a digital transformation, the company's value-creating activities often change, which requires adaptations to its whole business logic [2,6]. A company can have completely new opportunities in terms of how it creates, delivers, and captures value, which can lead 
to it having to review its business model and also which new markets or market segments can become relevant to them [3,4,6]. Iansiti and Lakhani [2] identify three characteristics that change business models. The first is that it is possible to send accurate data through digital signals. The second feature is that these data can be replicated as many times as possible without becoming corrupted. The third and final feature is that the cost of sending information decreases. Porter and Heppelmann [3] claim that it may be possible to acquire new revenue flows simply by collecting and selling further data to other stakeholders. It is then important that the company has secured the rights to these data and that who owns the collected data is already investigated before it happens. Here, partnerships of various kinds can be an advantage, because partners can have other ways of collecting data and data analysis that favors a collaboration $[17,18]$.

It is crucial that the corporate structure also follows the technical advances of the digital transformation, as old working methods, processes, and products and services surely need to be adapted $[4,6,19]$. One challenge that a company can face is that it may not have the proper competencies to carry out a digital transformation [5]. Thus, one of the strategic factors to take into consideration is to decide who will develop the digitized system and product-from the physical unit to the network, cloud services, analysis of large amounts of data, and the security aspect of the system [3].

\section{2. eMaintenance}

In industries where maintenance work occurs, it is critical to quickly determine the cause of faults and perform preventative maintenance [10]. At the same time, the subjective assessments that arise when several different individuals collect data manually can be reduced [13]. This makes it easier because, during maintenance, it is also important to make the correct diagnosis, not just a diagnosis, in order to save time and money [10]. eMaintenance enables more efficient and better maintenance work, as it can reduce remedial maintenance, which in turn leads to reduced costs, as unexpected errors can result in increased downtime [20]. Preventive maintenance, in which parts are changed per time intervals and thus creating risks when changing functional units, can be reduced by the preventive maintenance being developed toward state-based maintenance, which enables eMaintenance.

Kaiko-Mattsson et al. [11] describe how organizations that move to eMaintenance must ensure the ability to exploit the right technology at the right time. If this cannot be solved, the benefits of eMaintenance will be greatly reduced. The collection of data should be of high quality; otherwise, it will not be possible to obtain reliable output values in eMaintenance [21]. A common problem with the use of computerized systems for monitoring maintenance is the large amounts of data that are collected, making the systems complex, and that these data are spread over different systems [10]. The systems must be able to handle many different functions that are important when it comes to maintenance such as work orders, inventory, and various parameter values [22].

Education and training within an organization are given a critical status in order to achieve a good eMaintenance system, as knowledge and capacity are a company's greatest organizational assets [11]. It is also discussed how this is the most resource-intensive and complex part. Kaiko-Mattsson et al. [11] describe that this point consists of the preparation part for getting work started on eMaintenance, and the training part to get the right knowledge in the right person. Furthermore, questions such as who should be trained in what and for what purpose and who should be trained before the other should be answered. Aboelmaged [23] denotes the importance of working with what benefits the implementation provide, in order to be able to inspire the organization to change.

\section{Methodology}

In order to answer which capabilities need to be taken into account when eMaintenance is to be implemented, which results from this, and what links exist between these factors, a qualitative research method was applied. Because the research area is young and the study wants to contribute to the gaps identified, an exploratory research target was chosen [24]. Alpha and its client was chosen as a very suitable company for this case study, as it is working with digitalization and digital 
transformation which is a perfect fit to the purpose of this study [25]. Alpha is a technology and IT consulting company for societal development, and this case study focused on one of the units, which works more specifically toward railway operations. This gives valuable access to experts, developers, and users of digitization and rail maintenance. In addition, this unit at Alpha supplies contacts to the Governmental Railway Authority, which is the country's largest railway manager and one of Alpha's largest customers. Apart from the fact that the Governmental Railway Authority is the county's largest railway manager, it also manages the traffic management on the national railway, which gave this study the proper access to all relevant stakeholders, information, and informants. In addition, the Governmental Railway Authority is undergoing a heavy digitization work in various areas, which made this case especially relevant to the study because application areas are comparable. This further ensured that the study received more angles from respondents who are employed at different companies but also at different positions and roles in the digitalization process. Digitalization commonly involves several actors to manage competence appropriately, and therefore is this case a valid representative to study digital transformation.

Data were collected through interviews and access to documented material, to give the study depth and investigate the problem from several perspectives and add flexibility $[24,26]$. Several data sources were also used to carry out a so-called triangulation, in order to increase the paper's credibility [25]. Also, to further understand the problem and the research question in depth, the respondents selected in consultation with Alpha proved information-rich. A total of 26 35-to-80-min interviews were conducted (an overview can be found in Table 1).

Table 1. Explorative and Semistructured Interviews.

\begin{tabular}{cccc}
\hline Respondent & Working Area & Company & Time (min) \\
\hline R1 & eMaintenance & University & 55 \\
R2 & Digitalization & Alpha & 55 \\
R3 & Strategic development & Railway Authority & 50 \\
R4 & Aperation and maintenance & 60 \\
R5 & Signal condition & Railway Authority & 55 \\
R6 & Maintenance, technology and environment, switches & Railway Authority & 60 \\
R7 & Investigations, signal & Alpha & 35 \\
R8 & Level crossings & Railway Authority & 60 \\
R9 & Strategic development & Railway Authority & 55 \\
R10 & Alpha & 60 \\
R11 & Digital working methods, design & Railway Authority & 80 \\
R12 & Railway system, condition analysis & Railway Authority & 70 \\
R13 & Upgrading railway system & Alpha & 55 \\
R14 & Digital working methods & Alpha & 50 \\
R15 & Digitalization & Railway Authority & 40 \\
R16 & Strategic development, innovation & Railway Authority & 45 \\
R17 & Systematic electricity, signal, rail & Railway Authority & 50 \\
R18 & Functional responsibility facilities & Alpha & 35 \\
R19 & Digital working methods, assignment management & Alpha & 45 \\
R20 & Digital working methods & Railway Authority & 60 \\
R21 & Plant monitoring & Railway Authority & 50 \\
R22 & IT monitoring & Railway Authority & 45 \\
R23 & Plant monitoring & Railway Authority & 50 \\
R24 & Rail condition & Alpha & 50 \\
R25 & Business models & University & 60 \\
R26 & eMaintenance & Railway Authority & 40 \\
\hline
\end{tabular}

The interview questions followed an interview guide; however, depending on the respondents' work area, the questions that received the greatest focus during the interviews were varied. The semistructured interviews were recorded and then transcribed. The respondents were selected partly in consultation with experts but also through snowball selection to obtain a good breadth of perspectives [27]. 
The last two interviews were conducted as follow-ups to validate the preliminary results from the collected empirical data. The preliminary result was presented, and then a discussion was held with the respondents about this. In order to obtain as much information as possible from the follow-up interviews, the respondents were selected based on their expertise.

In parallel with the interviews, these collected data were analyzed (i.e., comparative analysis) [28] and then transcribed. After the first interviews had been transcribed, they were read through, and initial thematic codes were created. The codes were then discussed using pattern comparisons to form themes [25]. The coding was also used to categorize different concepts and thoughts that emerged in the interviews with the help of designations. All parts of the coding and analysis were initially made separately and then compared and discussed to improve the breadth and depth of the analysis [29].

Validity and transferability was ensured by providing a richness of details from all parts of the study Detailed descriptions of the applied method including the case selection, selection of the respondents, and data analysis, the complete records for each phase of the research process have been kept and could be accessed by other researchers. Multiple authors jointly conducted interviews and have been involved in the analysis of the data. For example, coding schemes have first been developed independently by the researchers, and in the event of disagreements, they discussed and modified the coding scheme until consensus was reached. Interviews from multiple respondents from different companies have been conducted to increase the transferability of the study.

\section{Results and Analysis}

The following chapter presents the collected empirical data from the qualitative study. It consists of three different parts: (1) the important capabilities that should be taken into account when eMaintenance is implemented; (2) the outcomes of implementing eMaintenance; (3) capabilities used to develop a framework to create a better understanding of its relationship with each other.

\subsection{Capabilities for eMaintenance Implementation}

By examining the opportunities and challenges that exist within the Governmental Railway Authority when implementing eMaintenance, the themes with associated codes that are most relevant capabilities to make decisions were identified (see Figure 1). Identified themes that have the greatest impact on implementation of eMaintenance were analyzed and selected as important capabilities. Selected themes include management of information security, handle regulations and monitoring, utilize digital technology, coordinate organizational development, and changing working methods. 


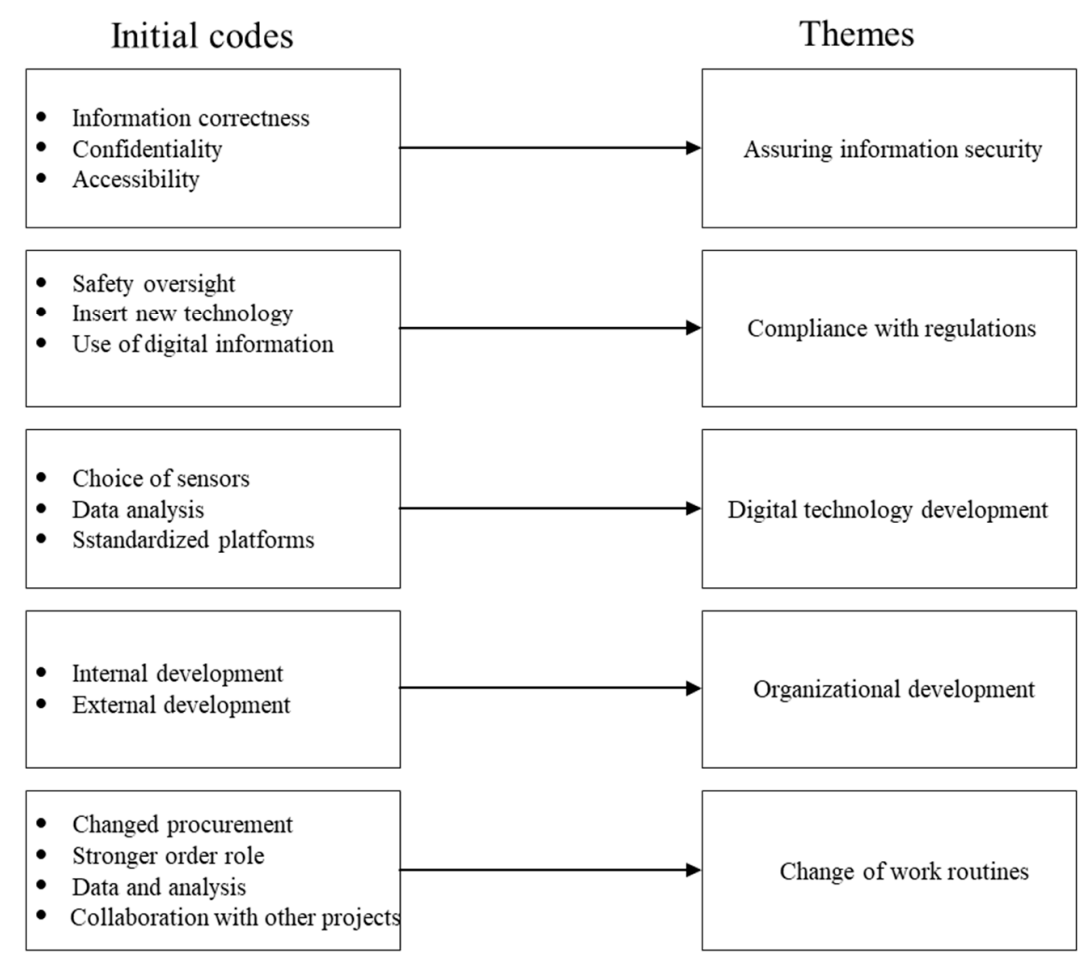

Overarching dimension

Figure 1. Capabilities for eMaintenance implementation.

\subsubsection{Assuring Information Security}

Information security, hereafter referred to as security, is a common theme for all respondents; furthermore, it is maintained that this is one of the most important parts to work with. At each time and event, safety aspects must be considered, and, because the degree project case study is within the railways, which to some extent is classified as security for the national security, this is understandable. Many of the respondents argued that security is an issue that is becoming more and more relevant and is increasingly being raised during meetings and discussions. The security will be consistent throughout all parts of the work of digitizing maintenance. Several respondents also believe that security will be further expanded from the current level and, as an example, gave the scandal to the Governmental Transport Authority and its data handling [30]. Key aspects of security as noted by respondents included correctness, i.e., that the technology itself cannot be hacked and cause damage or accidents in the plant. The second part included confidentiality, i.e., to limit who has access to the systems, so that highly classified information does not reach the wrong person. Both of these issues need to be considered when storing and accessing information but also when transmitting information. If the sensors are connected to a safety permit, additional safety rules are added. Accessibility is also important; that the security does not limit the possibility of getting information to the people who are entitled to the information and get value out of it because, then, the value of digitization can quickly decrease.

"We try to get as much as possible open because there is no purpose to keep things secret. It must somehow be to achieve the purpose of protecting its site then." $-R 8$

Respondents agree that managing confidentiality is important; that there must be security classification of data for several reasons, including kingdom security. At the same time, there is also political pressure that information should be available to all; therefore, the information with low classification must be able to be opened up without affecting information with a higher security rating. Respondents also emphasize that it is natural but that there are not enough routines around this at present when it comes to digital technology and information. There is also a challenge in finding the balance in protecting the right data while some should be left open, per the respondents. 
Another difficulty may also be that, precisely because these data are to be sorted when they are to be classified as security, it will result in an extra step, which can potentially affect the digitization of railway maintenance. This is an aspect that respondents consider should be considered.

Another important aspect of data collected is accessibility, i.e., who should have access to it. Respondents agree that, in order to get as much value as possible, the right people need access to the right data. Therefore, it is important to assess what kind of information is necessary for which party. Open systems significantly increase the degree of innovation and can lead to radical and unexpected innovations. Several respondents argue that the Governmental Railway Authority previously had an open view of what kind of information it makes available; now, however, it seems to go the other way. Solutions that emerged during the interviews were that it is possible to allow needs-tested access to certain actors when they need certain information and, in this way, are able to maintain security. Safety must also follow the Governmental Railway Authority's own regulations and requirements. Some respondents, however, were concerned that the human factor could be a problem with regard to security if the correct routines were not followed, as they consider it to be the greatest concern with regard to classified information.

"I think we have had a very open view of this. Our systems have been very open. Of course, you have had to request access to them and so on, but it has been quite easy to access them then. But I want to say that this is history now because I hear vibes within the Governmental Railway Authority that even for us it will be an incredible tightening of what we as employees get access to and such. I think it will get even worse with it. What is external then external becomes even more difficult. So I think we will have a more connected world with regard to those systems." - R13

Respondents also addressed correctness, i.e., that information and data are not exposed to unauthorized intrusion. Respondents also highlighted the desire to develop, in parallel with the digitization of the maintenance, a smart security system that can see connections and help in the assessment of which data are considered safe and which data can be passed on. This applies not only to those who have access to these data but also how these data should be stored and sent between systems. Several respondents also agreed that the associated IT systems must be regulated and made secure so that they become difficult to get into for someone on the outside and emphasized that it is of great importance that the transmission of information and data is carried out in a secure manner. Respondents emphasized that the security of open systems remains problematic with regard to the railways because road safety must be prioritized in the case of safety classification. This issue must be reviewed in depth at a digitization.

\subsubsection{Compliance with Regulations}

Because information security is important when the risks of errors are great, it has led to the national railways becoming regulated. As the Governmental Railway Authority is a state, it is also affected by the prevailing policy regarding budget and assignments. It is also monitored by the Governmental Transport Authority, which is obliged to comply with rules for safety oversight in order to carry out both the traffic management and the management of the railway. It is this safety management system that then forms the basis of regulations. At present, two parts were identified in which the regulations are obstructing: (1) partly when new sensors are to be inserted in a plant or unit; (2) the use of data collected by sensors. A respondent further states that current regulations are written to work with analog parts, and that a change is required so that it is also adapted for digital sensors and its possibilities. Some respondents also pointed out that the Governmental Railway Authority needs to be faster and actually implement changes in the regulations to enable the digitization of maintenance, as it is currently taking far too long. One respondent also believes there should be room within the regulations to test new technology, such as sensors, because certain regulations can obstruct progress.

"There is a reason why the railways are regulated, that is, the consequences of an accident are great.

If two trains go into each other or if you get a derailment ... " $-R 4$ 
It is not easy to change regulations, as they are based on the Security Protection Act; further, EU directives and the safety oversight follow up on compliance with these laws (Swedish Transport Administration, 2015). During the interviews, however, it emerged that the regulations have, to some extent, begun to be rewritten already, and one respondent suggested that a digitization of the actual regulations should open up, for example, to new technology. This is because they would show more clearly what requirements are set and which maintenance measures will be suitable to take.

"For entering vehicles or new technology, one has to go through the permit process. I am sure we will find things when we are connected and digitalized, but it must be approved as well." $-R 12$

When it comes to inserting new sensors into the plant, several respondents argued that the regulations can currently be an obstacle against implementing eMaintenance and have to be rewritten to some extent in order for it to work more smoothly to insert new sensors into plants. Some argued that it was a minor problem, and some said they did not see any problem but that they were not so deeply familiar with the area. Overall, however, the view was that the regulations need to be updated in order to make better use of the possibilities of digitization. Respondents argued that, today, it is a long process to bring in new sensors; further, often a certain component that is approved by the regulations, rather than a component, must meet certain specific requirements. This makes it more difficult to insert and test new types of components because each individual component must first be approved. Some respondents also pointed out that, if new sensors are to be installed in the plant, it is important to remember that the new sensors must not damage the plant in any way. Should new sensors be inserted, then they must add value and not be inserted just because it is an opportunity.

"If you want to set a sensor to measure and the regulations put a stop, then you have to change the regulations so that you can set a sensor."-R9

When information about the state of the plant is collected digitally, the regulations also need to be changed for the use of digital data. The regulations need to enable the transition from physical controls to continuously collected data digitally, along with the rules on how often information about the state is collected and how it is then used to create value. Respondents offered a mixed picture of how the present looks about this. One respondent said that there are currently no clear rules for data management and that these must be worked out. Another respondent stated that there are certain agreements about which information may be passed on between the client and the person who performs the service. Other respondents considered that it is sufficient to update the current regulations, but that it is something that needs to be prioritized in order to be able to continue working with digitization.

"So now we have discussions about this with the ownership of data and sharing data. There is currently no clear regulatory framework that regulates it. So this is something we work with."-R24

\subsubsection{Digital Technology Development}

The technology part of digitizing maintenance is versatile. Most respondents believe that it is critical to start from the needs and value of the technology in question. Several respondents noted the importance of having credible data presented to stakeholders in the most intuitive way possible. Respondents also emphasized that the technology should be remedial and enabling. They further stressed that new components and systems used in the plant should not create more jobs than the technology is used to remedy; therefore, it also needs to be used properly. One of the difficulties the Governmental Railway Authority is faced with is that it is difficult to follow up on faults that have arisen, and all relevant information that is needed if the facility may not be reported in the current system; further, the information that is reported is individually interpreted when it is inserted into the systems. A respondent noted getting order into the facility and having the correct information coming to the right person, which typically does not happen in a sufficiently effective manner. The quality of 
the data collected must be high in order for the digitization to provide a value. The factors that the respondents most often discussed were the choice of sensors, the analysis of data, and the importance of having standardized platforms. These factors are described in more detail below.

"So then it is of course a challenge to maintain things that you do not really know about."-R19

When the sensors were discussed during the interviews, most respondents believed it was the cyber-physical unit they were talking about, which houses the sensor and related parts. One goal of using sensors is to remove the human factor in current measurements, but the respondents stressed that one must prove that the sensors then deliver greater credibility and that data collected using sensors can therefore maintain a higher quality. For purely maintenance purposes, the sensors placed out must not break down more often than the unit itself being monitored. The problem that exists today is that one does not really know which data are relevant to capture nor what needs to be measured in order to create value. Great importance is attached to carrying out tests to discover this but also to dare to bring the sensors out in order to start using them. An important aspect of this was to use existing knowledge among individuals who are experts on the unit that is to receive sensors, so that the sensors measure as correctly as possible from the beginning, and then work with properties and functionality. One way of working is to equip the plant with sensors at the beginning and then remove the sensors for a clearer picture of what needs to be measured. Data from the sensors need to be credible and reliable in order to be used by the Governmental Railway Authority and external parties.

"What is it that we want to measure? What is it we want to know about the facility?"-R21

The goal is to obtain better decision support and remove subjective assessments; then, well-qualified analysis is required for the collected data to make it more accessible and understandable. There are many analysis tools to use, i.e., examples that respondents raised were to create a digital twin of the plant that could be used as the basis for calculations. The analysis should be able to identify the root cause of the problem in order to carry out the correct maintenance and, at the same time, be able to identify errors as early as possible; thus, advantageously identifying faults before they occur.

The need to use standardized platforms was highlighted during the interviews. There need to be systems that can easily receive information via computers; further, the information in the system must be machine-readable so that information can easily be picked up by authorized parties. An example of a standardized platform was one that gathers raw data in a central location in a "data lake," where all raw data are stored, which can then forward this to a standardized platform that can extract the right data through analysis. Then, it can be forwarded to a standardized platform that will deliver decision support by delivering the right information to the right person at the right time. This would mean that companies that need information from the Governmental Railway Authority should be able to access and retrieve the required information. It is important that the user-friendliness of such systems is high, i.e., organized and simple to understand. If this is not possible, the systems cannot work effectively.

"And then it is about knowing how to get it [data] and how can I present it to different other systems and / or people. And there is a great challenge for the work." -R8

\subsubsection{Organizational Development}

All respondents agreed that pedagogical efforts are needed to change an organization, and to digitize the maintenance means that new roles, a new way of thinking, and new working methods will be required to obtain the maximum value from the change. The Governmental Railway Authority is defined by many of the respondents as a large and rather sluggish organization when it comes to changes. It will require a changed culture, new ways of working and new roles in the organization and to bring key people who understand both the whole and their role in this is vital to getting a successful project. Anyone who works within the organization will also be affected by this, and this development is described as cross-organizational or multiorganizational. It is also about bringing the market and the 
academy on this journey in order to maximize the value of the eMaintenance. The market, which carries out the actual maintenance work, needs to know how to relate to the new information and to the new possibilities that digitization allows.

\section{"To get this to work, the first step is a form of educational effort in its own organization."-R3}

The first issue identified with regard to internal work was the importance of having a common vision within the organization. This means that the entire organization works toward the same target picture. Some respondents also addressed the importance of having a common definition of digitization, as it is a broad concept, and not everyone shares the same views on what it means. This was clearly noted in the interviews, as different definitions of digitization were noted. Digitization of maintenance will change people's way of working; further, within the Governmental Railway Authority, the importance of changing the existing culture, attitude, and willingness within the organization was identified. There is a need to create a willingness to change and increase the enthusiasm through pedagogical efforts and to bring new people into the organization who possess the missing knowledge. The development of eMaintenance is described as long and endurance-demanding work, where pedagogical efforts are constantly needed to move the work toward the same vision. Another point discussed was that, in some parts of the knowledge and work on digitization, consultants could be used as aids to maintain focus on the part that is central to driving the operations at the Governmental Railway Authority. Today, there is a digitization strategy that the Governmental Railway Authority has prepared for the coming years.

\section{"The hardest and most challenging thing is to change people's way of working."-R12}

The external parties, through which contractors will make use of necessary information to carry out maintenance activities, also need to understand the value and how to use the opportunities with eMaintenance. The respondents also noted the importance of running joint development projects with the academy and the market to increase internal and external knowledge these collaborations can bring. The market, then, has to carry out the actual maintenance work; further, in order to get as much value as possible from the eMaintenance, it needs to understand its meaning. It also requires incentives from the Governmental Railway Authority to work with it. Furthermore, the market can, through common development, transfer more knowledge to the contractors' shoulders, which could potentially mean a changed working method and business model in regard to maintenance.

\subsubsection{Change of Work Routines}

In order to maximize the value of eMaintenance, it needs to be reworked, and new working methods for procurement of maintenance are typically required, which means there is also the possibility to become stronger in their order role. The working method of ownership of data also needs to be processed; this means an opportunity to coordinate with other projects to obtain a greater value. A number of respondents point out that there should always be a focus on what benefit and what value digitalization should lead to. The challenge is not only to focus on the technology but on the strategic idea just to see where it is possible to create value through the new opportunities that digitization provides. It is also important to discern where this value can be located. This is because the digitization will not be carried out just to be implemented; if so, it will not be a greater value in the end. One respondent also believes that one of the major challenges is not to focus on the technology but instead on the strategic thinking just to be able to see where value can be created.

"I would generally say with digitization, it is not the technical challenge really but the strategic idea.

I usually say, digitization or digitized products require a different mindset. One must be able to see and connect other services to the infrastructure that allows digitization." $-R 1$

For the digitization to create value, several respondents considered that a changed procurement around the maintenance contracts was required to obtain the greatest value from the eMaintenance. 
Initially, the model will remain unchanged and later grow naturally with the digitization when the Governmental Railway Authority as an organization and the market identify and dare to test new ways to procure the contracts. One idea from the respondents is to control the contracts with the help of functionalities rather than having concrete measures enrolled into the contracts, thereby enabling state-managed maintenance in a way that benefits the Governmental Railway Authority and its contractors. This gives the contractors greater freedom to resolve maintenance issues in the best way; further, they themselves benefit if they come up with more efficient solutions, which, in turn, can lead to more innovation. This would mean that the market, which often has more power to be innovative, would take care of maintenance development. Contract length is currently seen as being a difficulty as it comes to innovation because most maintenance contracts are only three to five years long, with the option of option years. A short contract length, along with the public procurement, can also make it difficult for contractors to dare to invest in the railway as it is not certain that it pays for them. Despite this, several respondents consider that this development has the most potential and would be the most favorable for all parties in the end. However, several respondents consider that the market is not yet mature enough for this eventuality, and that pedagogical efforts and collaborations among the Governmental Railway Authority, the academy, and the market need to be accomplished in order to reach this point. However, this type of contract is based on the fact that the plant condition is well-documented so that the contractors can start from the right information. The lack of this is something that the respondents see as a problem today.

"What I know is not really in place, it's the business model then. Will we thereby act on the entrepreneurs differently, that they will have incentives to translate this knowledge into their tenders." $-R 9$

Most respondents highlighted that the Governmental Railway Authority, regardless of the way it wants to proceed, must become clearer and acquire a stronger order role. The Governmental Railway Authority strives to be a pure client; thus, the contracts that are procured should be clear, so that entrepreneurs and consultants receive incentives to both follow the new development and to be innovative. A recurring problem is that it is difficult to order correctly and that the Governmental Railway Authority needs to get better at it in order to get the results it seeks. The respondents also discussed that, when the profit margins of the contractors are low, it uses loopholes in the contracts to increase margins, which makes contract design all the more important.

"You have to be a good contract writer, I think a lot is actually there. Because I think that exactly what

I mentioned with error remediation that they [the entrepreneur] earn more from it than to prevent, it is something loopholes they have found, I am sure of that." - R17

Digitization also enables new ways of working around the collected data, and that its data processing and analysis need to be addressed. A foundation repeatedly addressed by respondents was who should handle the collection and analysis of data, who has access to it, and who then holds the ownership of it. Respondents also talked about the fact that external actors can be used to collect data but that basic data collection should be handled by the Governmental Railway Authority. Data can be collected and analyzed by the Governmental Railway Authority itself, which means that it also becomes the owner of this data. After this, the results of the analysis are sent out to the contractors. This option means that improvements and development of new analysis tools are done internally. A couple of respondents argued that there is hardly any sense in subjecting the maintenance to competition, if the entrepreneurs in principle only compete on pay and logistics, and that the degree of innovation would remain low.

"It will be a completely new way of working. For that we see for our part too. How much more information we should create and generate. This means that someone should take part of that information and handle that information and return the information." -R10 
Several respondents also mentioned the importance of creating better coordination with other projects. On the other hand, the collaboration within the industry needs to be reviewed; however, in regard to long-term planning and maintenance, one respondent questioned this as being a more short-term part. Some respondents argued that large profits could be made if the time in tracks could be reduced. If the maintenance can be coordinated with other activities, that mean the traffic is stationary, the time in the tracks could be reduced, and, with that, even large costs would be reduced. Better and more reliable data could make it easier for the Governmental Railway Authority to precisely plan its maintenance activities and thus reduce the time in the tracks.

"Actually, it is the planning perspective that needs to exist on several levels than it does today. Today, there is a little too much downpipe in that. And we act when it happens, and when things happen yes then not all of these things are in place to do many other good things. So it's an inefficient use of work windows or unforeseen events that make the railroad stand still anyway." $-R 20$

\subsection{Outcomes of eMaintenance Implementation}

Respondents, based on their understanding of the possibilities of eMaintenance, describe the result they wanted to achieve. The section is categorized according to the themes identified: increased information on conditions; increased capacity; improved maintenance; optimized costs; and increased sustainability. These are illustrated in Figure 2 below, where the initial codes are described on the left and themes on the right.

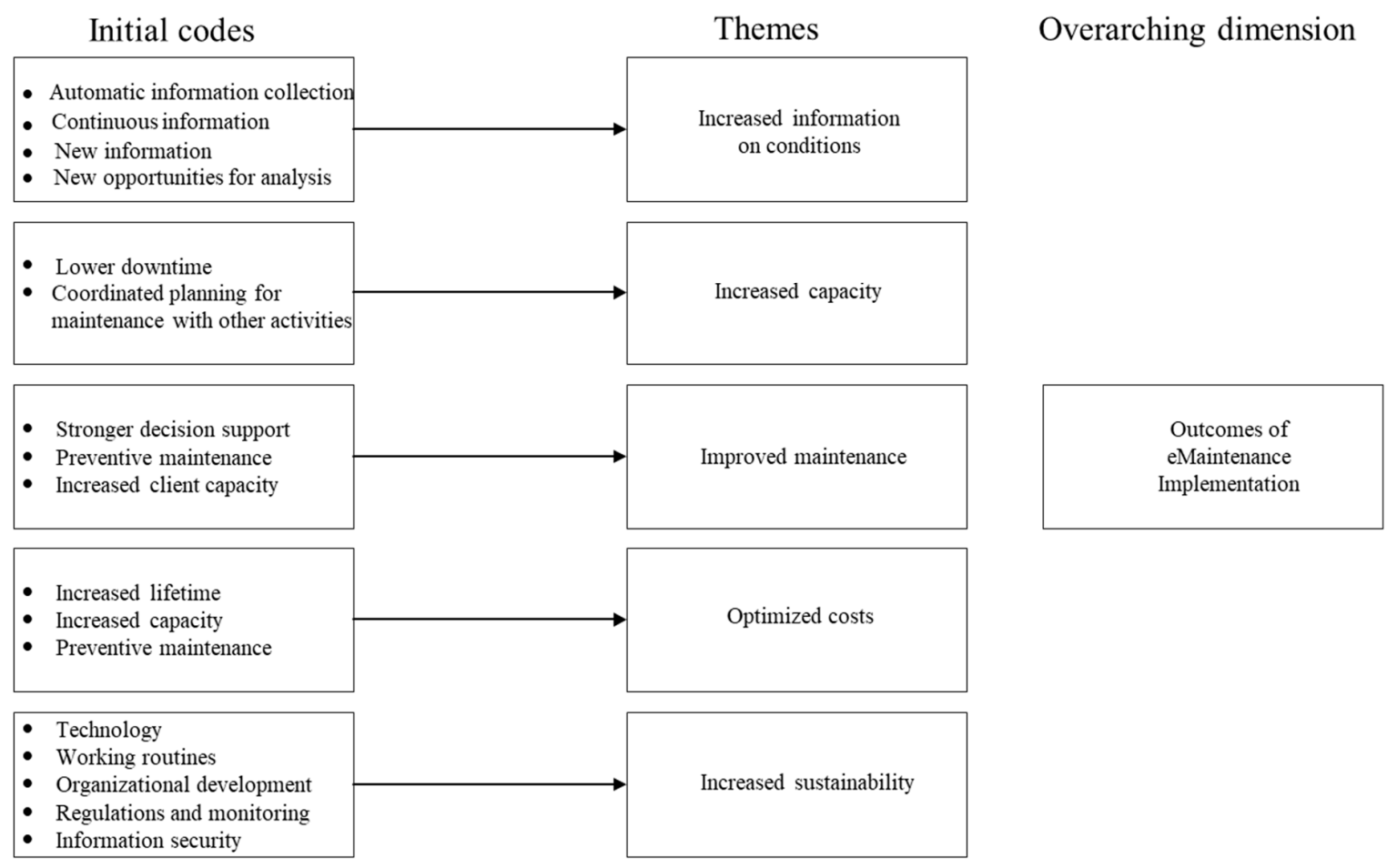

Figure 2. Outcomes of Implementing eMaintenance.

\subsubsection{Improved Information on Conditions}

Respondents identified that better and more continuous information in regard to the state of the plant is an opportunity for digitization. One problem with the current means of gathering information about the facility is that it has been subjective, and the human factor plays an enormous role in the result. Instead, using mechanical information gathering gives an impartial result, which can also be collected continuously. Through mechanical information gathering, one can also identify and retrieve more information that was not previously possible. The information collected can be used on new 
analytical methods, which gives an even better understanding of the state of the plant. The result of this is that one receives an increased understanding and increased information about the state.

"Greater mechanical handling will be the case, to get rid of variations when people do things. There will be more mechanical handling, more controlled on automation." -R11

\subsubsection{Increased Capacity}

When one can better plan the maintenance, the downtime also decreases, as error-correcting maintenance decreases. When the maintenance is planned, it is possible to coordinate the activity with other measures to be done at the facility. This contributes to increasing capacity, as it reduces the number of stops required in the plant. By doing the right maintenance, one can also increase a plant's service life.

"If we do measures without conflict with the train traffic, we also have a facility that is more accessible, so we are not in the way when the trains will roll." -R15

\subsubsection{More Efficient Maintenance}

The digitization of maintenance provides a greater opportunity to do the appropriate maintenance at the designated time. The transition to state-controlled and planned maintenance also leads to more efficient maintenance, as one will obtain a clearer picture of which maintenance action needs to be done and partly a time span when it needs to be done. The information on the state of a device will be typically reliable and credible and helps to get a stronger decision basis. By having a better basis, organizations can also order maintenance at their facilities better, using the available documentation.

"My picture of my future there is that we have an infrastructure that makes a self-diagnosis, and describes how you feel. For example, I [the plant] is doing well, but now the load has become so high so now I need to get action done."-R15

\subsubsection{Optimized Costs}

Downtime costs money. Reducing downtime also reduces maintenance costs. Even more efficient maintenance optimizes the costs of maintenance by, for example, reducing the time required in tracks, which is something that respondents identify. An advantage of implementing the right type of maintenance at the right time also increases the plant's service life.

"Simplifying my everyday life and making money from it, saving money or seeing it. That you can maintain more rail for money that you usually say so nicely." - R11

\subsubsection{Increased Sustainability}

As the work on eMaintenance proceeds, continuous development of the various factors will take place through synergy effects between them. The work on eMaintenance does not end, as it is typically an ongoing development. If one of the factors is changed through new knowledge, there is the possibility that others are changed to maximize value creation. Because the maintenance is made more efficient, waste, for example, on incorrectly used materials, decreases when maintenance measures take place, and that the service life increases, which leads to increased environmental sustainability. For example, an entrepreneur does not have to physically examine a unit's condition and can instead obtain the information via sensors, something that hijacks gasoline emissions for travel. Economically, an organization will save large sums of money on maintenance through being more efficient. In the Governmental Railway Authority's case, it is directly the society that saves these large sums; further, it also saves time for travelers who would otherwise suffer a delay, which increases social sustainability.

"Increasing digitization is the obvious, economically sustainable, sustainable rail traffic, greater accessibility, greater openness and increased collaboration to optimize the entire system. And a connected facility provides continuous control of the condition." $-R 12$ 


\subsection{Framework for Implementation of eMaintenance}

When maintenance is to be digitized, it is necessary to analyze the main capabilities and take a stand on issues surrounding them in order to implement digitization of maintenance on the framework as presented below (which consists of two parts, according to Figure 3). The external parts of regulatory and supervision and information security must continuously be a foundation when decisions are to be made regarding the work and development with digital technology, changed working methods, and organizational development that also affect each other.

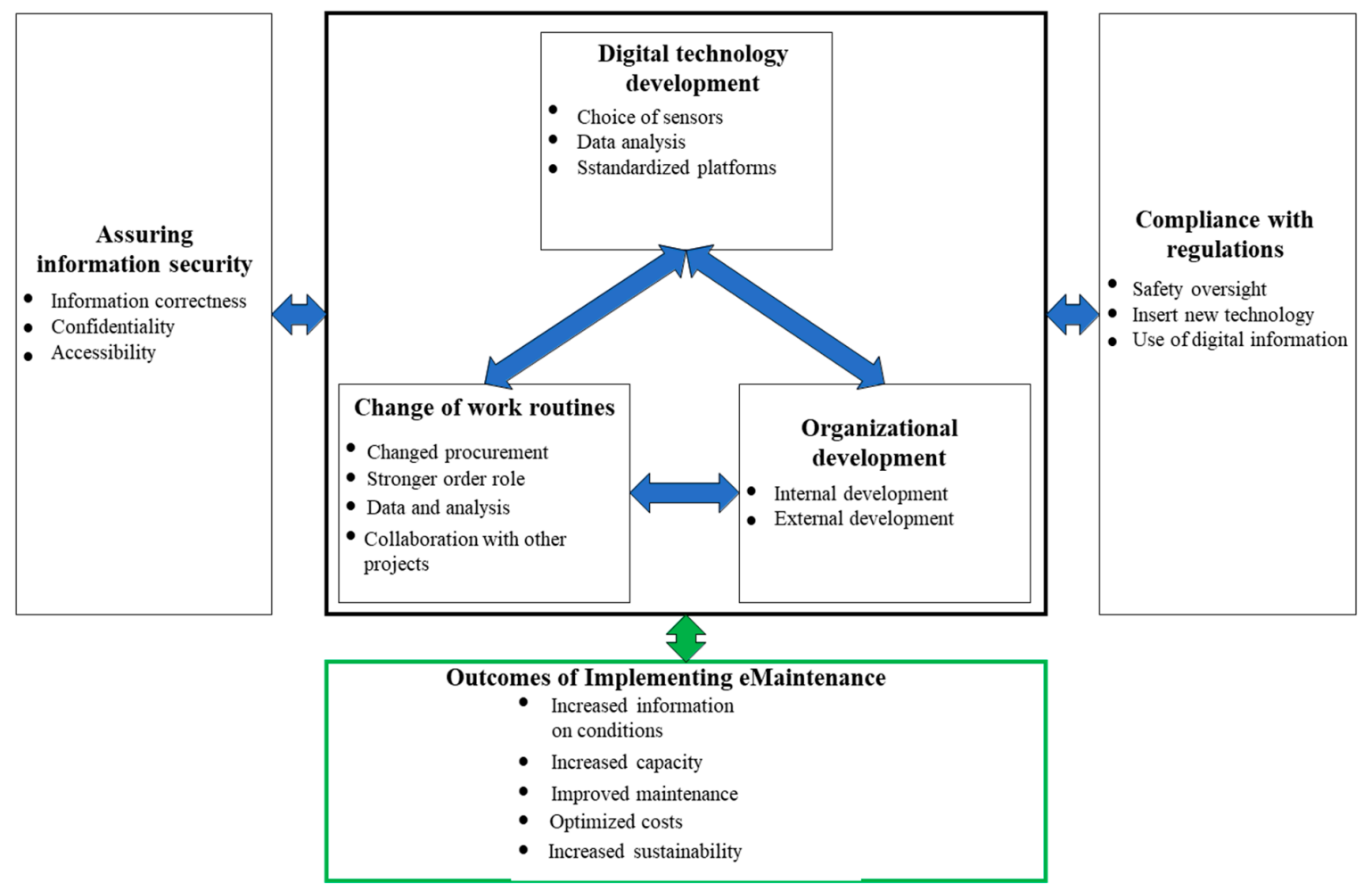

Figure 3. Framework for Implementing eMaintenance.

Information security management is a key focal point when work on digitization is in progress. It is important that classified information about the facility does not reach the wrong people; however, at the same time, it is accessible to the right people. Some data require a high security rating, but it is also equally important that the information that can be released does so in order to promote development, innovation, and enable the work required. Routines are also important for those allowed to access information and that these routines are complied with; this in order to create security in the organization and show outward reliability. In the framework, we therefore consider that security needs to be considered all the time when new technology, working methods, and organizational changes are developed and implemented.

Because regulations and monitoring can have a large impact on which changes that may and may not be implemented, this is also something that affects all other parts. The regulations must therefore be followed but also updated where they have been able to be outdated in relation to the digital development. In order to carry out digitalization of maintenance, it is important that the regulations are rewritten in order to enable tests and the insertion of digital devices, so long as they do not compromise with the security. Even the use of the information requires rules that make sure that it is used correctly, and, because the information changes when it transfers from analog information collection to digital, the regulations surrounding it also need to be updated. Therefore, we see that the regulations together with security affect the other parts of this framework, as this is something that is the basis for the others. 
The choice of the appropriate digital technology is vital for being able to carry out digitization. Collection of information digitally reduces errors as a result of subjective assessments, which is a risk if it is collected manually. Thorough thinking about the choice of which sensors to use needs to be carried out, so that each sensor becomes value-creating. Then, analysis tools need to be linked to the information that the sensors send; furthermore, the information from the analysis needs to be made available through standardized platforms that can take in and forward information. This is important so that the right information becomes available to the right person in the right place. Based on the information, a better decision-making basis can then be created so that the right type of maintenance can be carried out and enable preventive maintenance. With sufficiently good analysis, a transition to state-based maintenance can eventually take place, which can lead to more efficient maintenance. The development of the technology means that new working methods are made possible, and new roles in the organization will have to be created to manage and utilize the new technology.

In order to utilize the new opportunities created by eMaintenance, the maintenance methods need to be changed. If new maintenance strategies are to be used to enable, for example, permit-controlled maintenance, then maintenance procurement needs to be changed. This in itself requires that the organization be able to do the procurement in a way that benefits the organization and the contractors who manage the maintenance. Decisions and strategies about who owns what data and how it is to be collected and analyzed will also be required. Because maintenance is preventative and more planned, maintenance can also be co-planned with other measures to reduce downtime. As the working methods are developed as a result, the need for new roles and knowledge within and outside the organization can be identified. There may also be identified the need for new technology to facilitate the working methods, which further develops technological facets.

The implementation of eMaintenance requires that an organization develops and manages the changes taking place. For one, it is about bringing the organization through educational initiatives; it is also about cultural changes and another way of thinking, i.e., new ways of working that require new roles. It helps to have a vision and a common goal for the development work. This development should take place together with the academy and the market in order to make it as smooth as possible. External parties who work against the organization, such as the contractors who carry out the maintenance themselves, will also need to be developed in order to take advantage of the value of the eMaintenance. If the organization is involved and helps entrepreneurs with the development by showing the meaning of the development and creating incentives for change, this means that the contractors have the opportunity to change their working methods and business model for the maintenance work, which enables them to capture the maximum value of the eMaintenance. Because the organizational development takes place, people with the right skills in the right roles can work with the technology development and correspond with the development of new working methods.

Once these factors have evolved and synergies occur between them, the actual outcome of eMaintenance can be identified. The technology itself can continuously provide improved information about the condition. This is linked to working methods that can act on the information that capacity increases due to reduced downtime. The maintenance is made more efficient as the improved information leads to stronger decision-making data. With this, the transition to more preventative and, above all, state-controlled maintenance can take place and be ordered against contractors in an optimal way. Due to the correct type of maintenance, the service life of the plant also increases, while the maintenance is planned better and the capacity increases, which leads to cost optimization. Finally, it is described that the continuous work on the identified factors will lead to increased sustainability. Reducing unnecessary material consumption or unnecessary travel to identify the state of units is thus implemented. The economic sustainability is achieved via efficient maintenance saving costs for maintenance and, at the same time, increasing plant capacity. 


\section{Conclusions}

This section discusses the study results, which includes theoretical and practical contributions. The report concludes by describing limitations and recommendations for future research. There are countless opportunities when it comes to eMaintenance, which have also been discussed in the literature $[10,11,20,23]$. In this report, we have therefore designed a framework for which capabilities are crucial when an organization wants to implement eMaintenance; we also identified the outcomes that arise when the transition to eMaintenance has been carried out. The study has contributed to the research through several theoretical and practical measures.

\subsection{Theoretical Contributions}

The first contribution is the identification of capabilities when implementing eMaintenance. The five identified capabilities (i.e., digital technology development, organizational development, change of work routines, compliance with regulations, and assuring information security) build the foundation of our framework. This advances previous literature by going beyond opportunities and challenges of digital technologies $[5,14]$ by preparing the organization for the digital transformation. During the study, it became clear that the management of information security and regulations and monitoring are a primary challenge when implementing eMaintenance; further, to the best of our knowledge, previous literature has not highlighted this issue as strongly as our study has identified $[5,7]$. The literature has previously mentioned that information security is an aspect that is becoming more and more relevant; therefore, it is a natural step to highlight the technology where it has previously been a factor to focus on in our framework. The identified capabilities including information security are also for major relevance for other Industry 4.0 and IoT applications.

During the study, the outcomes of implementing eMaintenance were also identified, i.e., improved information on condition, increased capacity, more efficient maintenance, and optimized costs, which in previous literature only has been studied in isolation and not aggregated $[1,23,31]$. This qualitative study has produced the same results as previous research on the possibilities; however, in addition, increased sustainability was identified as a main driver for eMaintenance. This point highlights how eMaintenance contributes to a reduced impact on the environment, the economy, and people in a clearer way than previously [8,32]. We believe that, in order to get the most out of these effects, the framework needs to be used when a company wants to implement eMaintenance or Industry 4.0 initiatives.

The framework shows which connections exist between the main capabilities. The interrelationships contribute to continuous development of the capabilities through synergy effects. The framework helps to clarify these conditions, in which management of information security and regulations and monitoring were highlighted as the basis of the entire digital transformation, and how technology, working methods, and organizational development are then developed with that foundation. Many felt that this was only the beginning of the opportunities available with eMaintenance and that, through constant development and use, more opportunities will be identified. This is achieved through continuous development of the identified factors. eMaintenance is still a young research area in which our theoretical contribution is to link the theories that exist in regard to digitization and digital transformation with eMaintenance and further increase understanding of the research area and related topics $[33,34]$.

\subsection{Practical Contributions}

By showing which important capabilities should be developed to implement eMaintenance, management can know what to focus on and also see the synergy effects between the capabilities, which gives a better overall picture. We show the synergy effects that arise by letting the organization's development go hand in hand with the technology and the new working methods that are added where each part will help the others. The technology will enable more value creation; further, the organization should be able to take advantage of it, and the working methods should be able to deliver maximum 
value using the technology and organization that exists. In addition, the regulations and information security are the basis for which to show that these points are consistently at work with the other factors. The study also shows what the outcome will be of implementing eMaintenance. By being able to show the possibilities that exist with the implementation, stakeholders can be persuaded that this is a good idea and that the implementation should be implemented. Thus, this framework can be used as a tool to drive the development in the area ahead in the organization.

\subsection{Limitations and Future Research}

One limitation with this qualitative study is that it is implemented on a company in a specific industry. The focus has been on the maintenance of the railway within the Governmental Railway Authority. In addition, the Governmental Railway Authority is state-owned, which also affects the result to some extent as opposed to that of other private companies. This creates hard regulatory controls and means that the Governmental Railway Authority is responsible for a supervisory authority in order to carry out its task. However, this study has not investigated theories of regulations but shows that it is an important factor to consider. This could be verified by conducting a survey on other companies in the market, which are not state-controlled and where a need for eMaintenance, such as the mining industry, has been identified.

Another limitation is that the cost issue was not investigated. As the Governmental Railway Authority is governed by the state and allocated a budget, this delimitation was made early in the study. According to theories of digital transformation, the financial aspects are among the greatest driving forces for development ahead and affects the extent to which the various factors can be treated. Further research could investigate the links between economic factors and how well implementation of maintenance succeeds. Also, in the field of technology, there are more in-depth analyses to implement in theory than what has been done in this study.

Furthermore, the focus on security in this study has been aimed at information security. Other parts of the security, such as plant safety and traffic safety, can also be affected by digitization. Future research would therefore need to broaden the safety concept to include more different safety aspects. This can also be broadened beyond eMaintenance to Industry 4.0, IoT and other related concepts.

Future research in the field also needs to be carried out at companies that have already implemented eMaintenance, as opposed to ongoing implementation projects, as in this case to verify the results of this study. Future research should also examine the cost aspect associated with the factors identified. To be able to proceed with the work on the important factors, this transformation should also be demonstrated through a process that could facilitate the implementation for organizations.

Author Contributions: The individual contributions of the authors were divided as follows: conceptualization: N.J., E.R., and W.R.; methodology: N.J. and E.R.; formal analysis: N.J. and E.R.; writing and original draft preparation: N.J. and E.R.; writing, review, and editing: N.J., E.R. and W.R.; supervision: D.S.; project administration: N.J., E.R. and W.R.; funding acquisition: N.J., E.R. and W.R.

Funding: This research received no external funding.

Acknowledgments: We are grateful for the support provided by all participants of the study.

Conflicts of Interest: The authors declare no conflict of interest.

\section{References}

1. Müller, E.; Hopf, H. Competence Center for the Digital Transformation in Small and Medium-Sized Enterprises. Procedia Manuf. 2017, 11, 1495-1500. [CrossRef]

2. Iansiti, M.; Lakhani, K.R. Digital Ubiquity: How Connections, Sensors, and Data Are Revolutionizing Business. Harv. Bus. Rev. 2014, 92, 90-99.

3. Porter, M.E.; Heppelmann, J.E. How Smart, Connected Products Are Transforming Competition. Harv. Bus. Rev. 2014, 92, 64-88. 
4. Legner, C.; Eymann, T.; Hess, T.; Matt, C.; Böhmann, T.; Drews, P.; Mädsche, A.; Urbach, N.; Ahlemann, F. Digitalization: Opportunity and Challenge for the Business and Information Systems Engineering Community. Bus. Inf. Syst. Eng. 2017, 59, 301-308. [CrossRef]

5. Kiel, D.; Müller, J.M.; Arnold, C.; Voigt, K.I. Sustainable industrial value creation: Benefits and challenges of industry 4.0. Int. J. Innov. Manag. 2017, 21, 1740015. [CrossRef]

6. Matt, C.; Hess, T.; Benlian, A. Digital Transformation Strategies. Bus. Inf. Syst. Eng. 2015, 57, 339-343. [CrossRef]

7. Müller, J.M.; Kiel, D.; Voigt, K.I. What drives the implementation of industry 4.0? The role of opportunities and challenges in the context of sustainability. Sustainability 2018, 10, 247. [CrossRef]

8. Müller, J.M.; Buliga, O.; Voigt, K.I. Fortune favors the prepared: How SMEs approach business model innovations in Industry 4.0. Technol. Forecast. Soc. Chang. 2018, 132, 2-17. [CrossRef]

9. Li, F. The digital transformation of business models in the creative industries: A holistic framework and emerging trends. Technovation 2018, 79. [CrossRef]

10. Galar, D. Context Driven Maintenance: An eMaintenance Approach. Manag. Syst. Prod. Eng. 2014, 3, 112-120.

11. Kajko-Mattsson, M.; Karim, R.; Mirijamdotter, A. Essential components of emaintenance. Int. J. Pedagog. Innov. New Technol. 2011, 7, 555-571.

12. Riktlinjer för Anläggningsförvaltning (Asset Management) av digital tillgång (Cyber Asset); Luleå Tekniska Universitet: Luleå, Sweden, 2018.

13. Manco, G.; Ritacco, E.; Rullo, P.; Gallucci, L.; Astill, W.; Kimber, D.; Antonelli, M. Fault detection and explanation through big data analysis on sensor streams. Expert Syst. Appl. 2017, 87, 141-156. [CrossRef]

14. Stock, T.; Seliger, G. Opportunities of sustainable manufacturing in industry 4.0. Procedia Cirp 2016, 40, 536-541. [CrossRef]

15. Reim, W.; Parida, V.; Sjödin, D.R. Circular Business Models for the Bio-Economy: A Review and New Directions for Future Research. Sustainability 2019, 11, 2558. [CrossRef]

16. Yeow, A.; Soh, C.; Hansen, R. Aligning with new digital strategy: A dynamic capabilities approach. J. Strateg. Inf. Syst. 2017, 27, 43-58. [CrossRef]

17. Reim, W.; Sjödin, D.R.; Parida, V. Servitization of global service network actors-A contingency framework for matching challenges and strategies in service transition. J. Bus. Res. 2019, 94. [CrossRef]

18. Susha, I.; Grönlund, Å.; Janssen, M. Organizational measures to stimulate user engagement with open data. Transform. Gov. People Process Policy 2015, 9, 181-206. [CrossRef]

19. Reim, W.; Sjödin, D.; Parida, V. Mitigating adverse customer behaviour for product-service system provision: An agency theory perspective. Ind. Mark. Manag. 2018, 74, 150-161. [CrossRef]

20. Lee, J.; Chen, Y.; Al-Atat, H.; AbuAli, M.; Lapira, E. A systematic approach for predictive maintenance service design: Methodology and applications. Int. J. Internet Manuf. Serv. 2009, 2, 76-94. [CrossRef]

21. Aljumaili, M.; Wandt, K.; Karim, R.; Tretten, P. eMaintenance ontologies for data quality support. J. Qual. Maint. Eng. 2015, 21, 358-374. [CrossRef]

22. Tretten, P.; Karim, R. Enhancing the usability of maintenance data management systems. J. Qual. Maint. Eng. 2014, 20, 290-303. [CrossRef]

23. Aboelmaged, M.G.S. E-maintenance research: A multifaceted perspective. J. Manuf. Technol. Manag. 2015, 26, 606-631. [CrossRef]

24. Saunders, M.; Lewis, P.; Thornhill, A. Research Methods for Business Students, 6th ed.; Pearson: Harlow, UK, 2012.

25. Yin, R.K. Case Study Research: Design and Methods, 5th ed.; SAGE: London, UK, 2014.

26. Lancaster, G. Research Methods in Management; Routledge: Amsterdam, The Netherlands, 2005.

27. Onwuegbuzie, A.J.; Leech, N.L. A Call for Qualitative Power Analyses. Qual. Quant. 2007, 41, $105-121$. [CrossRef]

28. Leech, N.; Onwuegbuzie, A. Qualitative Data Analysis: A Compendium of Techniques and a Framework for Selection for School Psychology Research and Beyond. Sch. Psychol. Q. 2008, 23, 587. [CrossRef]

29. Bradley, E.H.; Curry, L.A.; Devers, K.J. Qualitative Data Analysis for Health Services Research: Developing Taxonomy, Themes, and Theory. Health Serv. Res. 2007, 42, 1758-1772. [CrossRef] [PubMed] 
30. Transportstyrelsen. Kartlägga Hanteringen av Vissa Uppgifter: Rapport till Regeringen. (TSG 2017-2515). 2018. Available online: https://www.transportstyrelsen.se/globalassets/kartlagga-hanteringen-av-vissauppgifter.pdf (accessed on 15 May 2018).

31. Iung, B.; Crespo Márquez, A. A review of e-maintenance capabilities and challenges. J. Syst. 2008, 6, 62-66.

32. Stock, T.; Obenaus, M.; Kunz, S.; Kohl, H. Industry 4.0 as enabler for a sustainable development: A qualitative assessment of its ecological and social potential. Process Saf. Environ. Prot. 2018, 118, 254-267. [CrossRef]

33. Parida, V.; Sjödin, D.; Reim, W. Reviewing Literature on Digitalization, Business Model Innovation, and Sustainable Industry: Past Achievements and Future Promises. Sustainability 2019, 11, 391. [CrossRef]

34. Reim, W.; Parida, V.; Örtqvist, D. Product-Service Systems (PSS) business models and tactics-a systematic literature review. J. Clean. Prod. 2015, 97, 61-75. [CrossRef]

(C) 2019 by the authors. Licensee MDPI, Basel, Switzerland. This article is an open access article distributed under the terms and conditions of the Creative Commons Attribution (CC BY) license (http://creativecommons.org/licenses/by/4.0/). 